\title{
COOPERATION ENTERPRISES -UNIVERSITIES- STUDENTS IN MACEDONIA AFTER BOLLOGNE DECLARATION - CONDITIONS, PROBLEMS, CHALLENGES AND SOLUTIONS
}

\author{
Dr Tale Geramitchioski* \\ University St.Clementius of Ohrid, Technical faculty, Bitola, Macedonia
}

The work gives image of the real condition of the cooperation between the business sector and faculties of technical sciences in education of mechanical engineers obtained through appropriate researches by using the instrument of survey questionnaire. The results point out defeated facts of total absence of cooperation, miss out in creation of study programs and profiles of mechanical engineers who graduate and who are not compatible with the market demand. The research enabled making difference of future challenges and suggesting possible steps towards problem solution. As a result of the research, the Centre for Teaching and Adopting New Technologies (CETANeT) was establish as a new institution to provide a new concept for real and intensive cooperation between University, state and the enterprises in the field of quality high education.

Key words: Higher education, Mechanical engineer, Labor market, Education model for engineers, Professional competencies, University, Enterprises, Bologna declaration

\section{INTRODUCTION}

Since 2003 Republic of Macedonia is cosignatory of Bologna Declaration and is member of European group of countries with reformed high education [02, 04]. As a result of the declaration requirements, the high education has been integrated - the universities became integrated, three cycle system of high education $(3+2+3$ and $4+3+1$ ) introduced, credit transfer system introduced, mobility of students and teaching staff provided by inclusion in the European program, Bacillus and Erasmus Mundus, the level of quality control is raised by self-evaluation, evaluation and expert evaluation [03, 08]. Moreover, in two turns the ranging of the Universities was made by Shanghai Jiao Tong University.

However, the impression in the public is that the profiles of staff from technical vocations deriving from so reformed system do not accomplish with the standards and developing flows of the economy, in particular by the foreign investors in production sector [06, 02].

The reasons for this impression are of many layers, but it is necessary to prove it as well scientifically by using the methods and techniques of survey questionnaire with direct inclusion of the subjects. The researchers are realised at subject living and working in the cities in Pelagonia region in Republic of Macedonia located at the south-west in Republic of Macedonia where little less than $1 / 3$ of the total population lives, but $80 \%$ of the produces electricity is being produced there [01].

The employers consider that the education is inappropriate due to the obsolete curricula, methods and techniques being applied in the education.

Non-developed systems of communication among the education institutions and the business community in the Pelagonia region, as well as the lack of community participation in the educational programs with practical work, results with low level student preparation that is a key factor for the requirements of the labour market [01].

This means that it is necessary to have joint and synchronised participation of all parties. It is necessary to create measures for future developing and stimulating the small and the medium enterprises as a main employer in the region. Strengthening the local economy requires strong link of cooperation between all business sectors.

The education system is the key factor that should establish a solid structure and organization to enable 
its functional connection with the labour market. However, the education must not continue with the practice of taking care only for the preparation of the new working power but also to take place in upgrading the working skills of the more experienced. The modern set up of the education system must respect the principles of flexibility, functionality and openness. Its care must be for students, employees, unemployed and all that need educational upgrade skills. The dynamics of change in education system should follow the dynamics of changes in the necessary competences required by the labour market [09].

The functioning of the education system must be followed by redesign of the given curricula. The basic functions of the teaching method must be an accomplishment and effectuation of the unity that exists among the student, general knowledge, professional specific knowledge, rounded by the standards for competences for certain profession or vocation [10].

The education services must leave the world of formalised standards and normative, to exit the classroom and to connect with the world that requires those education services. The basis for connection of the labour market needs and education should be the social dialogue among all parties considered $[03,04]$.

\section{EVALUATION OF THE MANAGERS OPINION FOR ENGINEERING QUALIFICATIONS}

For the purpose of analysing the opinion and attitudes of the managers for capacity of future engineers to respond to the labour market needs the work covers instrument A3: SURVEY QUESTIONNAIRE FOR MANAGERS covering 50 managers-engineers from several big and small industrial and production-economy companies in Pelagonia region [07].

The engineering is a profession where the knowledge obtained by studying, the experience and practice, are united for the purpose of developing the capacities for solving the problem in the industry.

During the researching, the following methods are used: analytical -synthetic method, method of generalization and specialization , classification method, method of induction and deduction, method of proof and denial and descriptive method.

Within these methods, the following technics are used for empiric data collection: survey and subject analysis.

\section{RESULTS AND DISCUSIONS}

Furthermore there is a presentation of the quantitative results from the survey questionnaire - instrument A3.

The need of increasing the communication skills such as verbal and non-verbal communications with expert and non-expert public, technical discussion with professionals from other fields is being confirmed by the fact that $60 \%$ of the participants in the survey agree that they partially have communication skills, $32 \%$ communication skills and $8 \%$ do not have communication skills (Figure 1).

The need of improvement of the skills for qualification of the team work and the functioning of the teams is confirmed by that that $50 \%$ of the participants in the survey consider that the engineers are less qualified for team work, $32 \%$ are very qualified and $18 \%$ are not at all qualified for team work (Figure 2).

The fact that the engineers invest in their professional improvement is confirmed by the $66 \%$ of the participants in the survey and 34 are not interested for professional improvement (Figure 3).

The biggest part of the engineers $74 \%$ consider that they most often use the problem solving within their work, $12 \%$ case study, $8 \%$ researches and $6 \%$ project work (Figure 4). The education of the engineers must contain the basics for successful practical work, effective teaching and relevant researches in the field of engineering for the needs of economy.

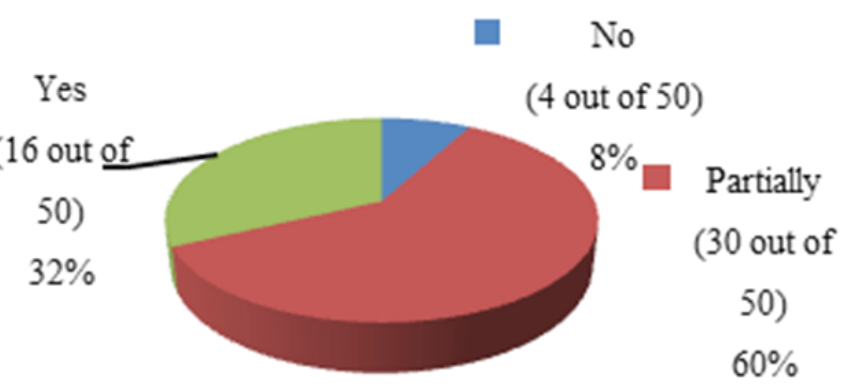

Figure 1: Does the engineers in your company own communication skills?

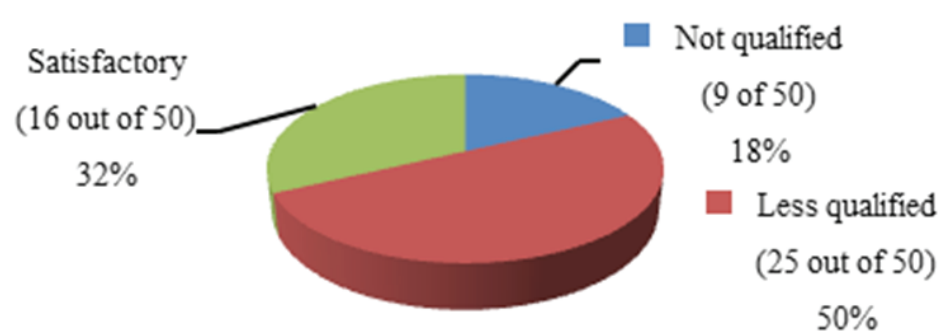

Figure 2: Team work capability of the engineers? 
The biggest part of the engineers $74 \%$ consider that they most often use the problem solving within their work, $12 \%$ case study, $8 \%$ researches and $6 \%$ project work (Figure 4). The education of the engineers must contain the basics for successful practical work, effective teaching and relevant researches in the field of engineering for the needs of economy. The existing program for education of engineers does not comply with the labour market requirements is confirmed by the opinion of the participants in the survey who consider that $62 \%$ do not comply with the labour market, while $22 \%$ consider that the curriculum less complies and $16 \%$ complies a lot with the labour market (Figure 5). The students the future engineers do not take the practical part in concrete companies. It is confirmed by the fact that $56 \%$ of the participants in the survey who consider that the students come rarely at practical teaching in their companies, $34 \%$ regularly come to practice and $10 \%$ consider that the students never go on practical work in their companies. The challenges bring changes in the practice and education of the future engineers that must be compatible with European standards. The cooperation between the universities and the industry must increase for the purpose of achieving better results regarding the quality of the graduated students for the preparation for the market (Figure 6).

The greatest part of the participants in the survey, $54 \%$ state that effective and efficient engineers are those with over 5 years working experience, $38 \%$ consider that effective and efficient are the engineers with experience from 3-5 years and 85 think that the engineers without working experience are effective and efficient (Figure 7).

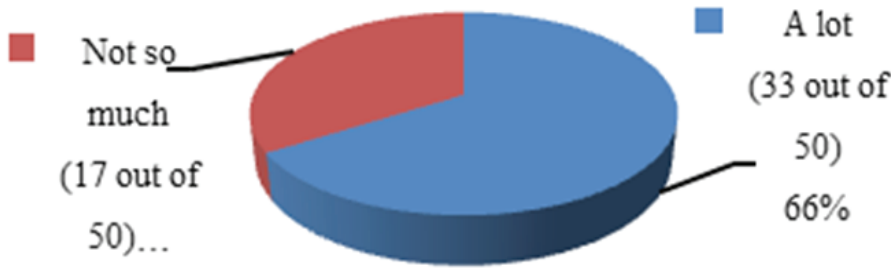

Figure 3: How much engineers invest in their proffesional improvement?

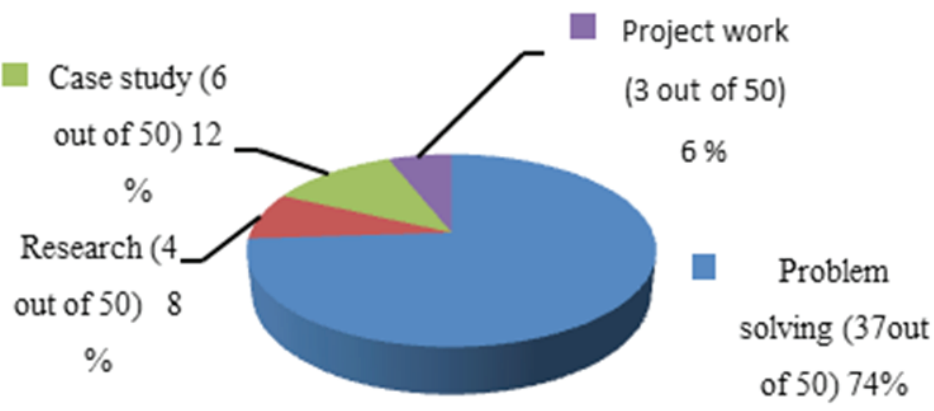

Figure 4: Activities that are most often used during work?

High level

(11 out of

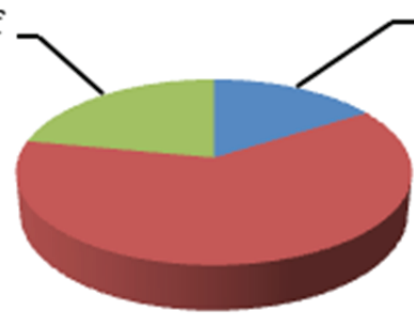

Does not

comply

(8 out of 50 )

$16 \%$

Low level

(31 out of

$50)$

$62 \%$

Figure 5: At what level engineer education program complies with the labour market requirerments?

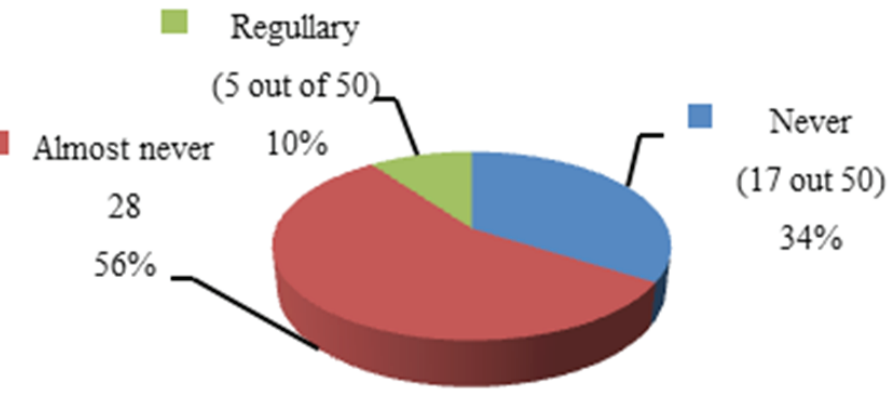

Figure 6: Do the students future engineers, take practical work in the companies?

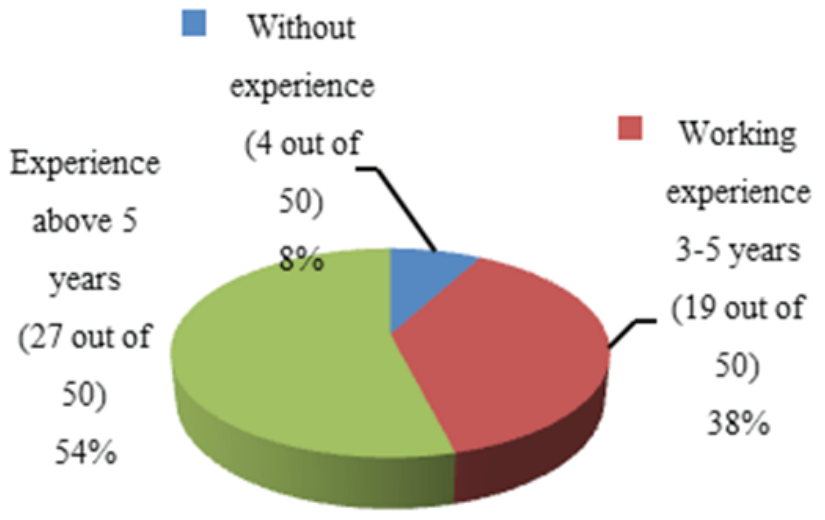

Figure 7: Which engineers are considered as efficient and effective? 
The research regarding the professional development of the students for the purpose of inclusion in the production that is in modern condition of the industry, showed that $63 \%$ of the participants in the survey consider that the students are less qualified to be involved in the production as the curricula do not comply with the labour market requirement, and $37 \%$ think that the students from the existing education system may be involved in the labour market (Figure 8).

Non-developed system of communication among the education institution and business community in Pelagonia region, as well as small participation of the community in creation of the educational programs and insufficient practical work during the education, result in low level of preparedness of students that finished their education for the purpose of inclusion in the labour market [07].

\section{CENTER FOR TEACHING AND ADOPTING NEW TECHNOLOGIES (CETANeT)}

This paper will introduce a new approach towards treatment of Enterprise-Student-University relationship with the purpose to increase the student and academic staff enterprise orientation and awareness. This approach will also enable higher level of harmonization of different curricula among partner institutions and at international level. This will increase the usage of new ICT technologies and business information systems models within the educational process, making it more efficient in the same time. On the basis of the positive experience of similar projects in Europe, it is expected that this approach will contribute to put into practice the process of development of partnerships between enterprises and University.

The interactive work-related lifelong learning proposed within the CETANeT will include two levels of organizational mechanisms, within and outside the University to foster an all-encompassing education through the blending of the ICT sciences with science and business education. These two levels of organization of the CETANeT are planned to be: executive board and implementation unit (Figure 9).

The executive board will be initially consisted of the managerial members of the project partners and the members of the endorsing enterprises, while in the future it is planed that this board will consist of members from all the participating entities in the CETANeTs enterprise-University net- work. This board will be the core of the CETANeT that will be responsible for producing schemes and concepts from which the implementation unit will work. The members of the executive board should continuously reinforce the main ideas on which the CETANeT will be built.

The scope of work for the executive board will assign these tasks:

- analysis of enterprise requirements and capacities/facilities of educational centres

- analysis of the enterprise information systems case studies

- analysis of the existing curricula and proposal of changes in existing courses

- introduction of new courses by defining the contents of the newly introduced courses

- definition of new technologies to be implemented in the distance/active learning and video-conferencing environment

The implementation unit will be consisted of mainly teaching staff and faculty members of the project partners. The members of the implementation unit should be well familiar with the active/distance learning and new technologies. This will ensure that the instruction and course content will be interactive, and the teaching will be flexible and creative.

The scope of work for the implementation unit will concentrate on the following tasks:

- implementation of course changes/new courses proposed by the executive board

- adjustment of learning materials to fit the needs of new technologies

- implementation of interactive distance/active learning and video-conferencing environment

- creation of interactive learning content into distance/active learning and video-conferencing environment

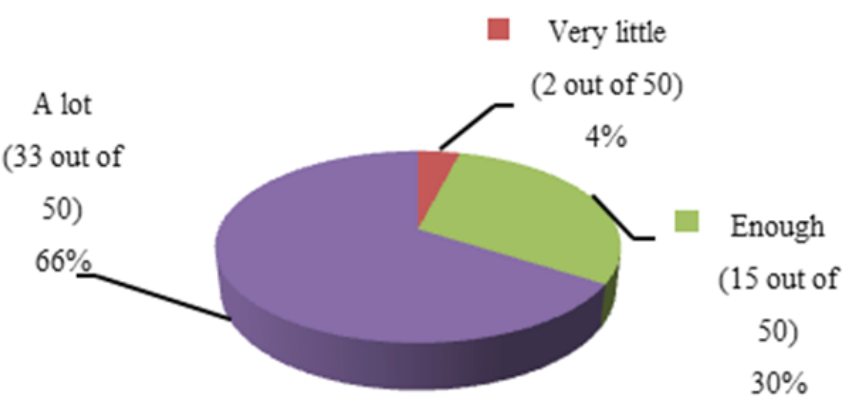

Figure 8: In your opinion how many students - future engineers are capable to be involved in the production process? 


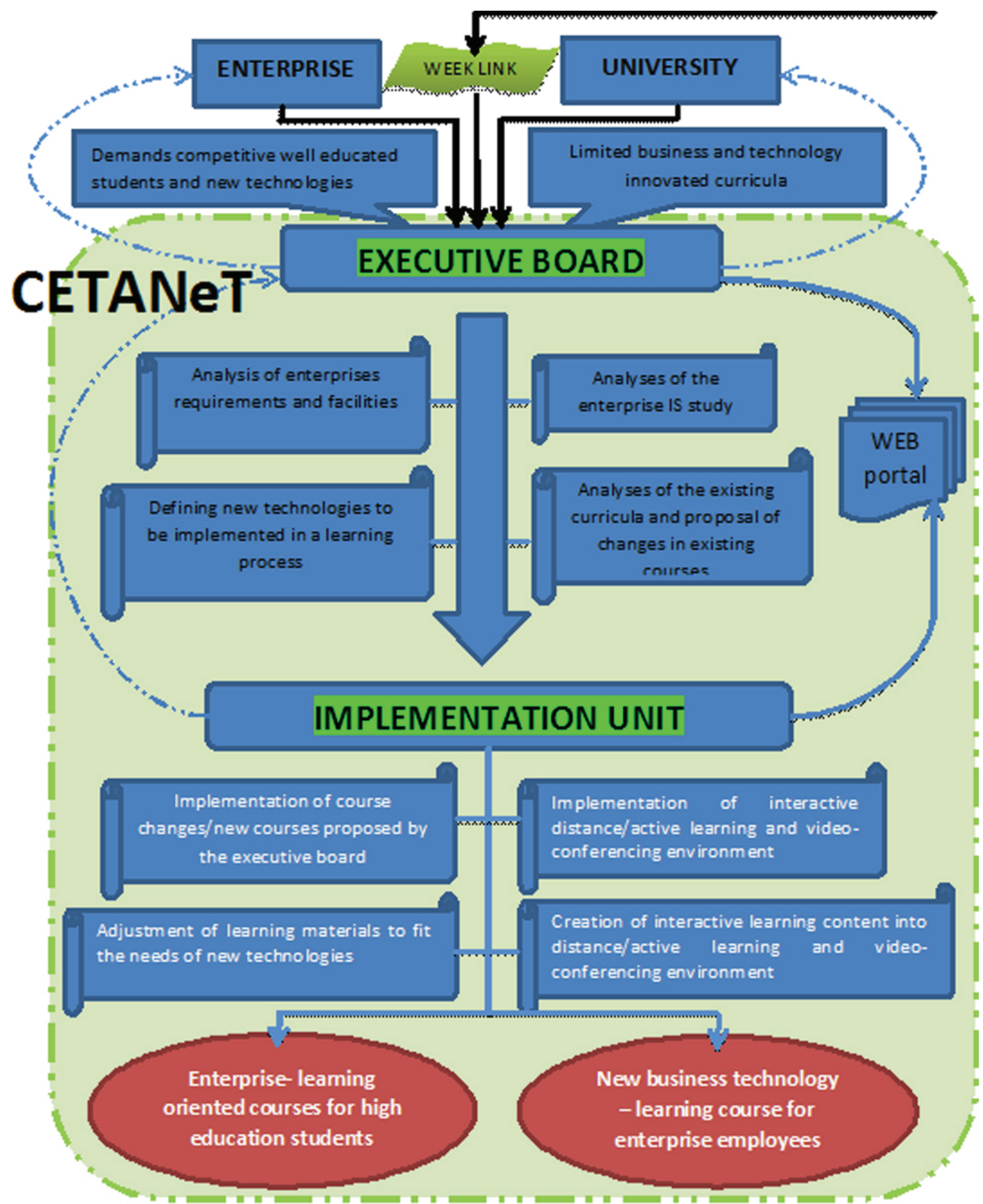

Figure 9: The conceptual architecture of the Centre for Teaching and Adopting New Technologies - CETANeT

Taking into account the CETANeT objectives and the organizational units tasks the main outcomes of the establishment of such centre will be:

- new business technology learning courses for enterprise employees

- enterprise-oriented learning courses for high- er education students

- creation of network of enterprise and University members

All outcomes are measurable by quantity of the changed or newly introduced courses and the number of enterprise employees and/or HE stu 
dents that participate in them, and the number of members in the enterprise-University network. The enterprise-University network will be hosted by the CETANeT web portal. Memberships of the network will be tied by formal joining the on-line community. The portal will also contain learning services (enriched with articles, cases, training exercises etc. in relation to CETANeTs main focus) developed by the implementation unit.

The target group of the project are students and faculty staff. The first ones should accept the usage of new technologies in the campus and increase their level of awareness and acceptance of the entrepreneurial world. The second ones should adapt to the newly introduced technologies and increase their level of communication with the enterprise community. The students will be involved in the evaluation of the project, while teaching staff should actively participate during the whole duration of the project.

\section{CONCLUSION}

Direct beneficiaries of the project will be the students and enterprises. The University will also benefit from this initiative by adopting the new technologies and business models that support the increase of the student and academic staff enterprise orientation and awareness in terms of transferring the tacit knowledge from industry to University and vice versa in order to strengthen the Enterprise-Student-University relationship. In that way, we expect that this proposal provides an environment that supports and increase partnerships between enterprises and University.

This project will also influence the lifelong learning process in the Republic of Macedonia. People need lifelong education opportunities to ensure that they will remain competitive in the workplace. The employees are supposed to get the needed technical skills and to be able to access online technologies for advanced training. Most of the employees that are supposed to use those technologies, and are ready to adapt to the new ones, have some kind of University based training. The establishment of the CETA$\mathrm{NeT}$ will be the basis for further development of an efficient partnership between University and enterprises and provide a lifelong learning educational framework.

\section{REFERENCES}

1) Business Start-Up Centre Bitola, The labour market in Pelagonia (Macedonia), Bitola, 2010

2) Communique of the Conference of European Ministers Responsible for Higher Education: The European Higher Education Area-Achieving the Goals, Bergen, May 2005.

3) Council of Europe, Legislative reform programme in higher education and research, 1991-2004, Strasburg, France

4) European Commission, Directorate-General for education and culture, Progress towards the European Higher Education Area, Brussels, July 2004.

5) European Association for Quality Assurance in Higher Education: Standards and Guidelines for Quality Assurance in the European Higher Education Area, February 2005.

6) Ministry of Education and Science of the Republic of Macedonia and the European Training Foundation ETF: "Proposal for a Strategy for Adult Education in the Republic of Macedonia in the Context of Lifelong Learning (2006-2015)", Skopje 2006.

7) Mitrevska C., Defining the Models for Engineering Education with Special Emphasis to Model for Engineer Design Education, PhD dissertation, University St. Clementius of Ohrid, Bitola, 2013

8) Regional University Network on Governance and Management of Higher Education in SEE, founded by European Commission and implemented by UNESCO-CEPES, National Policy of Higher Education in the Republic of Macedonia 2002-2005, Skopje

9) Schenk Brill, D. van \& Boots, P.J.H.M., 2001, Engineering, Experiences with Industrial Coeducation, SEFI Annual Conf. Copenhagen: 103-104.

10)Schenk Brill, D. van, Kollenburg, P.A.M. van \& Boots, P.J.H.M., 2002, Two Models of Engineering, Education for the Professional Practice, SEFI Annual Conf. Florence: 61-65

Paper sent to revision: 18.02.2015.

Paper ready for publication: 10.06.2015. 